Bangladesh J. Sci. Res. 28(1): 51-59, 2015 (June)

\title{
LEAD AND CADMIUM ACCUMULATION IN NEARBY BRICK KILN AGRI-ENVIRONMENTAL ECOSYSTEMS
}

\author{
Abdul Halim Farhad Sikder, Md. Delwar Hossain Molla ${ }^{1}$, Md. Faruque Hossain ${ }^{2}$ \\ and Zakia Parveen* \\ Department of Soil, Water and Environment, University of Dhaka, \\ Dhaka 1000, Bangladesh
}

\begin{abstract}
Three different brick kilns from the same parent material, young Brahmaputra and Jamuna floodplain were selected to assess the lead and cadmium accumulation. Soils and plants from four points such as 250, 500, 1000 and $1500 \mathrm{~m}$ away from kilns were collected based on the predicted brick kilns emission distance. Lead (92 $\mathrm{mg} \mathrm{kg}^{-1}$ to 214 $\mathrm{mg} \mathrm{kg}^{-1}$ ) was found in the elevated levels near brick kiln soils. The alarming news is that plant uptake of $\mathrm{Pb}$ in the nearest areas of the brick kilns were significantly higher than the areas far from the brick production location and $\mathrm{Pb}$ ranges from 7 to $543 \mathrm{mg} / \mathrm{kg}$. Results showed that both soils and plants from $500 \mathrm{~m}$ to $1000 \mathrm{~m}$ distance received maximum $\mathrm{Pb}$. The amount of $\mathrm{Pb}$ significantly decreases with the increasing distance from the brick kilns. Cadmium varies within the permissible limit in both soils and plant.
\end{abstract}

Key words: Lead, Cadmium, Accumulation, Contamination, Brick kiln, Agri-environmental ecosystems.

\section{Introduction}

Brick is one of the most attractive building materials in developing countries like Bangladesh where population is, highly dense, approximately 160 million. Due to rapid urbanization, construction industry is booming and spurred the production of 8.6 billion bricks per year with demand for the bricks rising at an annual rate of about $5.28 \%$ (UNDP 2011).

Trace heavy metals like As, $\mathrm{Cd}, \mathrm{Cr}, \mathrm{Co}, \mathrm{Cu}, \mathrm{Pb}, \mathrm{Hg}, \mathrm{Mn}, \mathrm{Ni}, \mathrm{Vn}$ and $\mathrm{Zn}$ along with many other elements are found in the ambient air of Dhaka city (Ahammad et al. 2010). One of the most important sources of air pollution in Dhaka city is thousands of authorized and unauthorized brick fields (Ahmed and Hossain 2008). Numerous scientists noted that a significant amount of toxic elements are being produced from brick kilns in every year (Pimentel 1993, Dowdeswell 1998, Khan et al. 2006), some of them are mixed up with air and some are deposited in soil. A large portion of these toxic elements, is heavy metals, are responsible for soil degradation. The plants act both as "accumulators" and "excluders".

Lead and cadmium are very much harmful for both living and non living environment, which can cause adverse effects on human health and agi-environment (Pirkle et al. 1998). Lead is accumulated by the living organisms but this metal is less mobile in soil due to less mobility of $\mathrm{Pb}$ which remains in the top soil (Martin et al. 2014). At high $\mathrm{pH}, \mathrm{Pb}$ tends to precipitate. Organic matter plays a vital role in $\mathrm{Pb}$ accumulation in the top soil by forming chelates (Sipos et al. 2005).

*Corresponding author: <zakiaparveen1@yahoo.ca>. ${ }^{1}$ Soil Resources Development Institute, Ministry of Agriculture, Farmgate, Dhaka, Bangladesh. ${ }^{2}$ American International University-Bangladesh, Kamal Ataturk Avenue, Banani, Dhaka 1213, Bangladesh. 
Cadmium is one of the most dangerous carcinogenic elements and is mainly produced by anthropogenic activity which moves easily to the food chain through soil to plant root absorption and accumulates an appreciable amount in the living body without showing stress. As a heavy metal like $\mathrm{Pb}$, Cd behavior is more or less same in soil. Cadmium can be mobile in both high and low pH (Cavallaro and McBride 1980).

Very little work has been done to assess the pollutants nearby brick kilns and their effects on agri-environment (Pimentel 1993, Ahmed and Hossain 2008) but none of the work has been done on $\mathrm{Pb}$ and $\mathrm{Cd}$ accumulation in soils and plants in agri-environment nearby brick kiln emissions. Therefore, the current research aims to find out the impact of $\mathrm{Pb}$ and Cd accumulation in nearby brick kiln agri-environmental ecosystems.

\section{Materials and Methods}

Three sites were selected on the basis of soil parent material, cropping pattern, and wind direction from the brick kiln to the field. Medium high land type is used as selecting criteria because of its influence on cropping pattern and farming system (Table 1). Sites are located in three different districts such as, Mawna (Gazipur), Kalampur (Dhaka) and Noyadingi (Manikgang).

Table 1. Description of the sampling sites.

\begin{tabular}{|c|c|c|c|c|c|c|c|}
\hline Site & District & Parent material & Land type & $\begin{array}{l}\text { Wind } \\
\text { direction from } \\
\text { the brick kiln }\end{array}$ & $\begin{array}{l}\text { Cropping } \\
\text { pattern }\end{array}$ & $\begin{array}{l}\text { Age of the } \\
\text { brick kiln } \\
\text { (year) }\end{array}$ & $\begin{array}{l}\text { No of } \\
\text { kilns }\end{array}$ \\
\hline Mawna & Gazipur & $\begin{array}{l}\text { Young Brahmaputra } \\
\text { and Jamuna } \\
\text { floodplain }\end{array}$ & MHL & $\begin{array}{l}\text { From brick } \\
\text { kiln to south }\end{array}$ & $\begin{array}{l}\begin{array}{l}\text { Boro } \\
\text { (HYV)- }\end{array} \\
\text { winter } \\
\text { vegetable }\end{array}$ & $12-14$ & 5 \\
\hline Noyadingi & Manikganj & $\begin{array}{l}\text { Young Brahmaputra } \\
\text { and Jamuna } \\
\text { floodplain }\end{array}$ & MHL & $\begin{array}{l}\text { From brick } \\
\text { kiln to south }\end{array}$ & $\begin{array}{l}\text { Boro } \\
\text { (HYV)- } \\
\text { maize }\end{array}$ & 14 & 3 \\
\hline Kalampur & Dhaka & $\begin{array}{l}\text { Young Brahmaputra } \\
\text { and Jamuna } \\
\text { floodplain }\end{array}$ & MHL & $\begin{array}{l}\text { From brick } \\
\text { kiln to south }\end{array}$ & $\begin{array}{l}\text { Boro } \\
\text { (HYV)- } \\
\text { maize }\end{array}$ & 8 & 5 \\
\hline
\end{tabular}

Soil and plant samples were taken from the agricultural fields adjacent to the brick kilns exposed to the different degrees of environmental pollution in February, 2014. Four distances from each area were selected, such as 250, 500, 1000 and $1500 \mathrm{~m}$ based on the predicted brick kilns emission distance. At each point, soils were collected from three layers such as surface (0 $15 \mathrm{~cm})$, subsurface $(15-50 \mathrm{~cm})$ and substratum $(50-100 \mathrm{~cm})$. Three replicate samples were mixed thoroughly to make a composite sample. Plant samples (10 - 15 plants) were collected from the respective field from where the soil samples were collected.

Properties of the collected soil samples are represented in Table 2. The parent material of all three sites was young Brahmaputra and Jamuna floodplain. Results demonstrates surface, subsurface and substratum soil of the study area are mainly silt loam in texture and is favorable for 
agricultural practice (Hannan 1995), where clay percentage is $<10 \%$ in most cases. Young Brahmaputra and Jamuna Floodplain soils are traditionally very low to low in organic carbon and CEC. The variation of OC may occur due to extensive agricultural practice and the application of less organic manures by the farmers. Most of the farmers denied using organic manures for crop production which is one of the most important reasons for OC variation in most of the rice fields. Intense farming pattern is also responsible for organic matter variation and there is another possibility of formation of cheleate with heavy metals producing from the brick kilns.

Soils are slightly acidic to acidic in nature in the sampling sites may be due to the application of excessive fertilizer and impact of nearby brick kilns. Brick kilns usually are emitting toxic gases, such as $\mathrm{SO}_{2}, \mathrm{NO}_{2}$ and some other compounds (Greentech 2012).

Table 2. Some soil properties of the sampling sites.

\begin{tabular}{llcccc}
\hline \multirow{2}{*}{ Sampling site } & \multicolumn{1}{c}{ Soil properties } & \multicolumn{3}{c}{ Sampling distances (m) } \\
\cline { 2 - 5 } Mawna & Clay (\%) & 250 & 500 & 1000 & 1500 \\
& Organic Carbon (\%) & 0.20 & 8.70 & 11.2 & 10.7 \\
& $\mathrm{pH}$ & 5.11 & 0.87 & 0.90 & 1.19 \\
& CEC (me/100g ) & 1.12 & 5.23 & 5.54 & 5.60 \\
\multirow{5}{*}{ Noyadingi } & Clay (\%) & 17.7 & 20.2 & 0.89 & 0.81 \\
& Organic Carbon (\%) & 1.14 & 1.19 & 15.45 & 5.20 \\
& pH & 5.22 & 6.14 & 6.62 & 0.7 \\
& CEC (me/100g ) & 1.14 & 1.10 & 1.17 & 1.08 \\
& Clay (\%) & 9.20 & 11.7 & 13.95 & 8.20 \\
& Organic Carbon (\%) & 0.68 & 0.68 & 1.07 & 1.24 \\
& pH & 5.04 & 3.44 & 6.05 & 5.57 \\
& CEC (me/100g ) & 0.69 & 0.51 & 0.89 & 0.89 \\
\hline
\end{tabular}

Total concentration of $\mathrm{Pb}$ and $\mathrm{Cd}$ was digested by Aqua rezia with a ratio of $1: 10$ (Jackson 1962). For the determination of available $\mathrm{Pb}$ and $\mathrm{Cd} 1 \mathrm{~N} \mathrm{HCl}$ was used as an extracting agent with a ration of $1: 33.33$ (Chowdhury et al. 2010). After the extraction both of the heavy metals were analyzed by AAS.

The data from all soils and plants were combined and analyzed statistically to examine the relationships between $\mathrm{Pb}$ and $\mathrm{Cd}$ with soil properties. In this approach statistical software strata version 12 was used.

\section{Results and Discussion}

Soils are silty loam in texture derived from parent materials young Brahmaputra and Jamuna flood plain; they have medium (20-30\% in clay fraction) mica in medium high land condition which refers to a medium CEC level of the soil. Availability of $\mathrm{Pb}$ and $\mathrm{Cd}$ in soil also depends on many other inherent properties of soil like CEC. Availability of $\mathrm{Pb}$ and $\mathrm{Cd}$ ultimately depends on the 
soils properties (Table 2). Correlation analysis shows that $\mathrm{Pb}$ and $\mathrm{Cd}$ increases with a decreasing $\mathrm{pH}$. The role of $\mathrm{pH}$ in controlling the $\mathrm{Pb}$ and $\mathrm{Cd}$ concentration in the soil solution is well known (Bur et al. 2012, Ming et al. 2012) and research data here also followed the same trends. Soil pH plays a major role in the sorption of heavy metals as it directly controls the solubility of metal hydroxides, as well as metal carbonates and phosphates. This phenomenon has been demonstrated by many researchers in a variety of temperate region soils. Besides these significant correlation values are also presented in regression format (Figs 1 and 2). Accumulations of these two metals were higher in the surface soils, where the accumulation of organic carbon is high. This organic fraction is slowly available in the soil indicates a significant relationship between organic carbon and availability of $\mathrm{Pb}$ (Fig. 3). Lead and $\mathrm{Cd}$ have a tendency to form chelate with the organic carbon (Sipos et al. 2005).
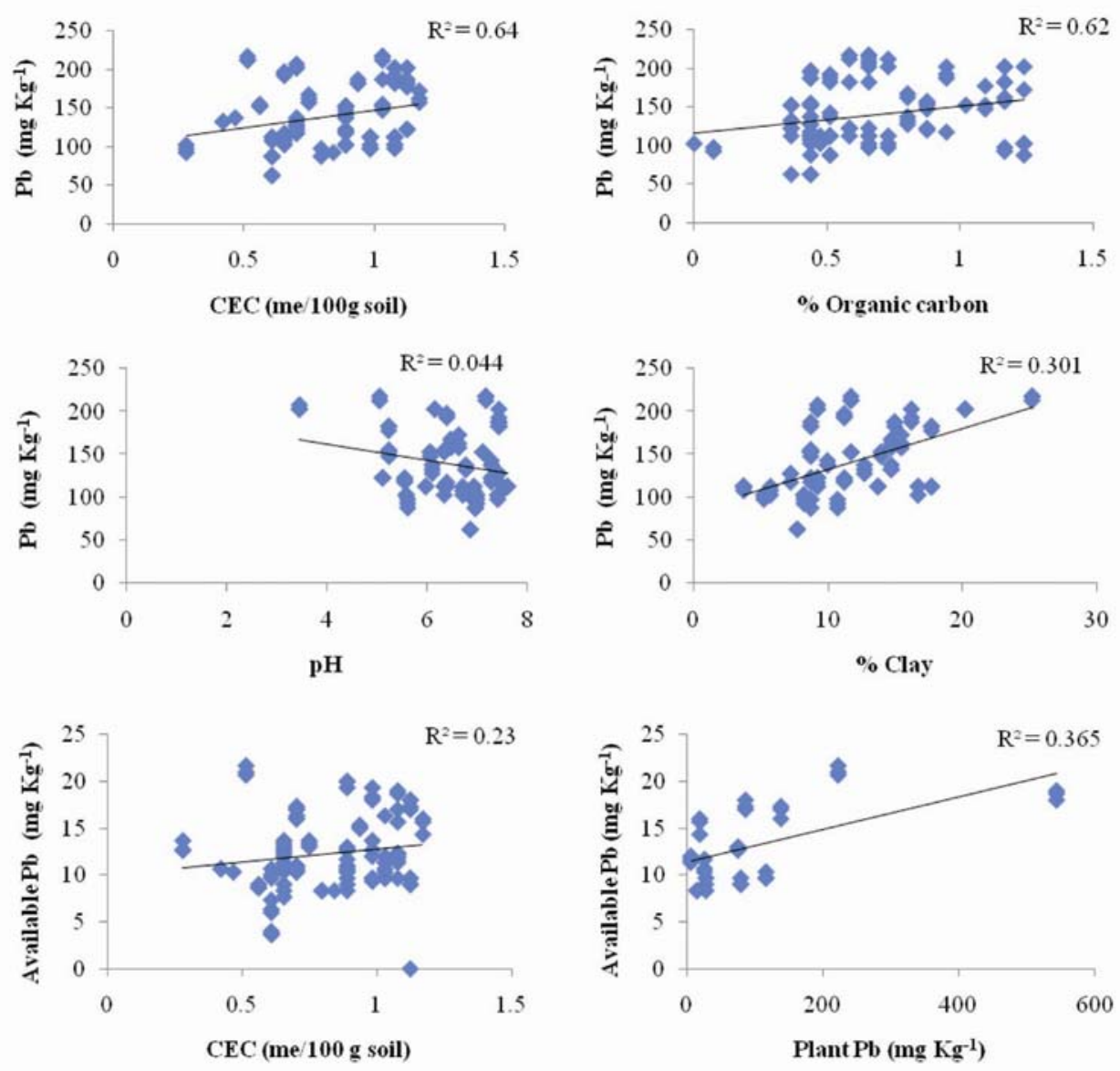

Fig. 1. Relationship between total Pb-soil constituents, available Pb-soil constituents and available $\mathrm{Pb}$ in soilplant $\mathrm{Pb}$. 
Accumulation of $\mathrm{Pb}$ was found to be highest in the $500 \mathrm{~m}$ distance from the brick kiln (Fig. 3 ), may be due to the dumping of fly ash in this zone. Fly ash or coal ash contains an appreciable amount of $\mathrm{Pb}$ and $\mathrm{Cd}$ (USEPA 2003). Therefore, when they fall in some places accumulation of these two elements may be higher. Accumulation of $\mathrm{Pb}$ and $\mathrm{Cd}$ in near distance from the brick kilns may also be supported by the lower $\mathrm{pH}$ (Ming et al. 2012). One of the main by product of the brick making operation is $\mathrm{SO}_{2}$, which lowers the $\mathrm{pH}$ when moves down to soil as a mixture with rain water. Heavy metals accumulations are significantly reduced with the distance (Figs 3 and 4). The most alarming message is the significant accumulation of $\mathrm{Pb}$ in the soils, whereas, $\mathrm{Cd}$ concentration is lower than the critical limit ( $<1 \mathrm{mg} / \mathrm{kg}$ ), but the $\mathrm{Pb}$ level is more than double in soil than the average level.
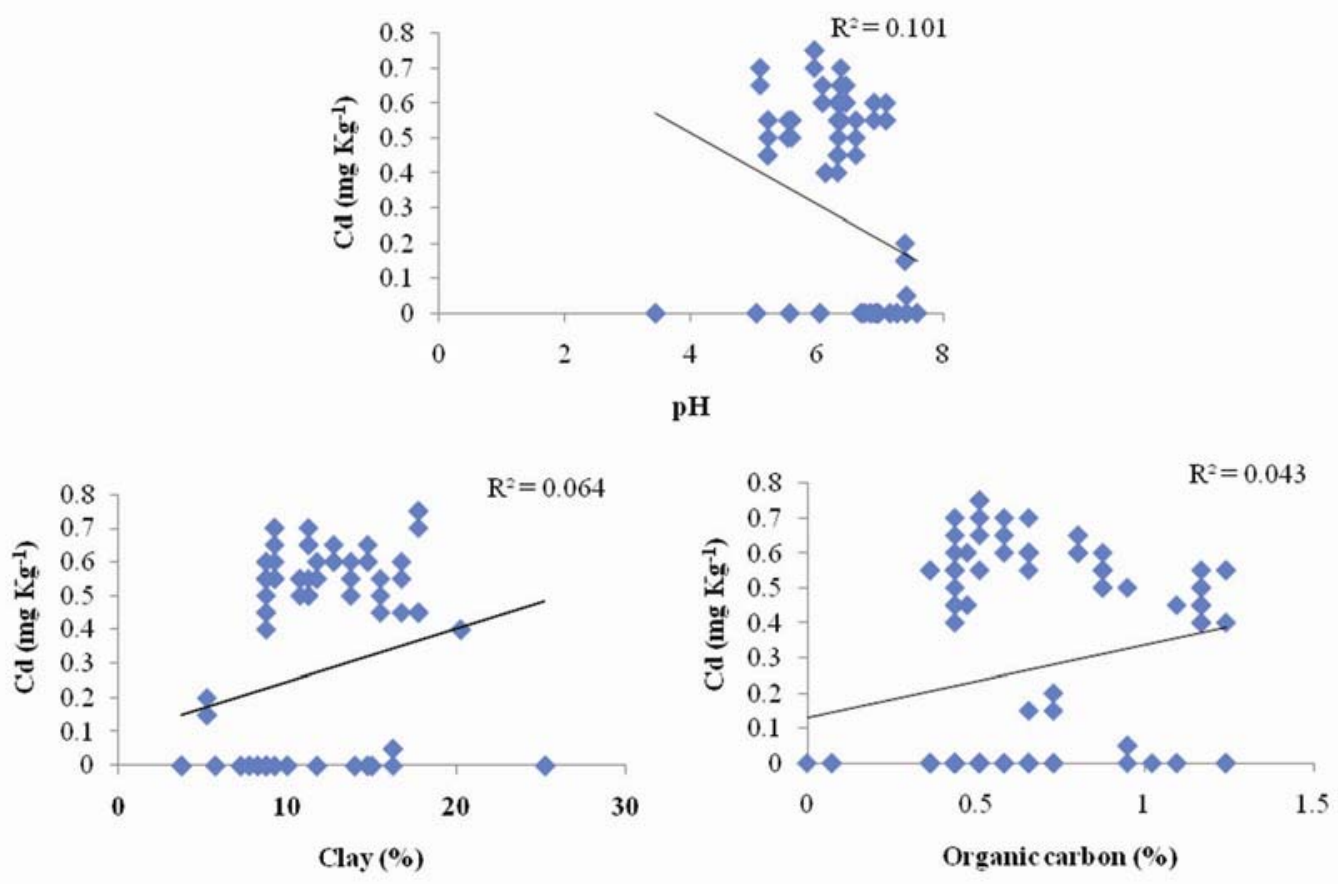

Fig. 2. Relationship between total Cd and soil properties.

Concentration of $\mathrm{Cd}$ was found trace and $\mathrm{Pb}$ was found higher than the critical limit $2 \mathrm{mg} / \mathrm{kg}$ (BARC 2005) in the plants of the sampling area (Fig. 5). Lead concentration in plants is an alarming matter because of its carcinogenic character. A strong correlation between available $\mathrm{Pb}$ concentration in soil and total $\mathrm{Pb}$ concentration in plant indicates that it is derived by low $\mathrm{pH}$, fly ash dumping from the brick kilns and organic matter presence in surface soil.

Plants, living in the affected areas were affected by both $\mathrm{Pb}$ and $\mathrm{Cd}$ in two ways. First, they take these from the air directly through respiration and secondly as a food substituent when conditions are favorable such as low pH, high CEC and organic carbon. These heavy metals are 
also responsible for biological toxication. It may also store in the agri-environment as a part of the biodiversity (Kleijn and Sutherland 2003). When herbivores eat these plants they get infected with the toxicities, is followed in every stage of the food chain and in the upper stage affect in more pronounced as bio magnification takes place in every single stage. Ultimately if the plants get affected with $\mathrm{Pb}$ and $\mathrm{Cd}$ all plants and animals are also affected.

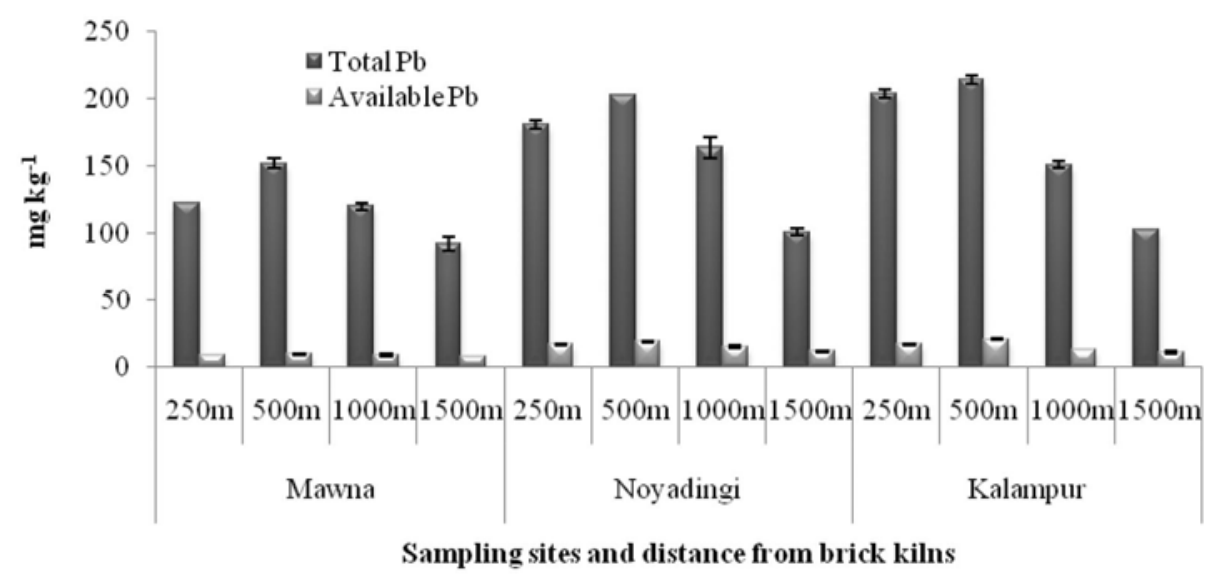

Fig. 3. Accumulation of total and available $\mathrm{Pb}$ at different distances from the brick kilns.

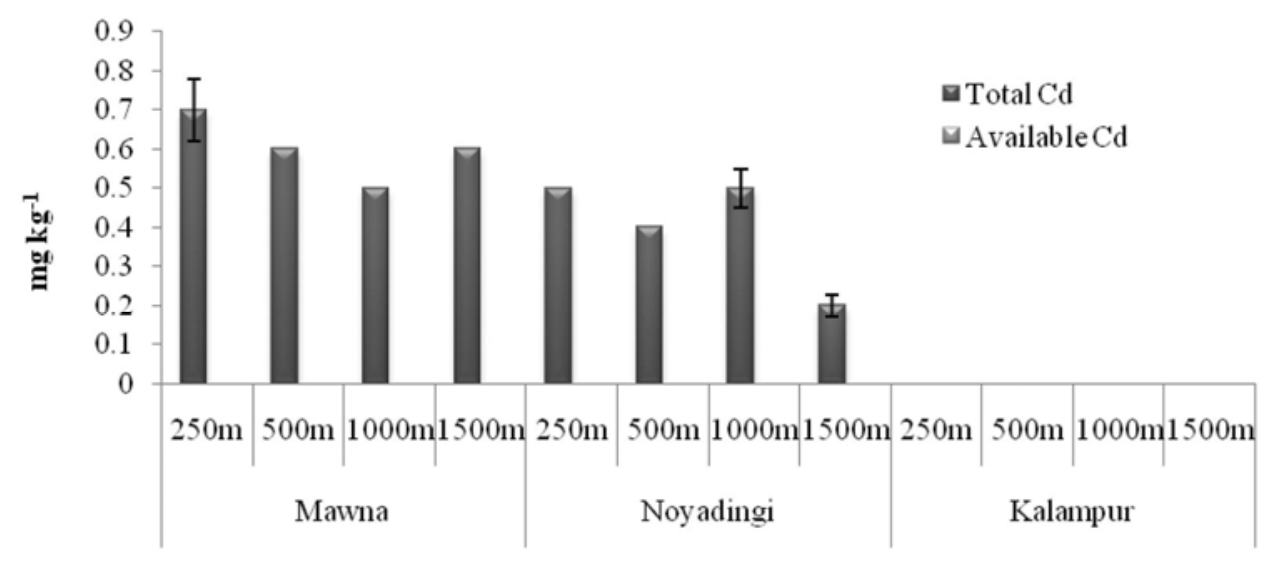

Sampling sites and distance from brick kilns

Fig. 4. Accumulation of total and available Cd at different distances from the brick kilns.

It is well known that important heavy metals posing threats to soil quality and human health include $\mathrm{Cd}$ and $\mathrm{Pb}$ and both of them are used for a wide variety of industrial, urban, and agricultural applications. Rural people and brick kiln workers exposed to low levels of Cd over time may incur kidney damage as well as lung, bone, cardiovascular system, liver, and reproductive system damage (Hrudey et al. 1995). In children, $\mathrm{Pb}$ has been known to cause 
decreases in IQ scores, retardation of physical growth, hearing problems, impaired learning, as well as decreased attention and classroom performance. In individuals of all ages, $\mathrm{Pb}$ may cause anaemia, kidney disease, brain damage, impaired function of the peripheral nervous system, high blood pressure, reproductive abnormalities, developmental defects, abnormal vitamin D metabolism, and in some situations death (Hrudey et al. 1995). The stronger the interaction of Cd and/or $\mathrm{Pb}$ with the surface soil, the less the likelihood of agri-environmental contamination (soil and plant).

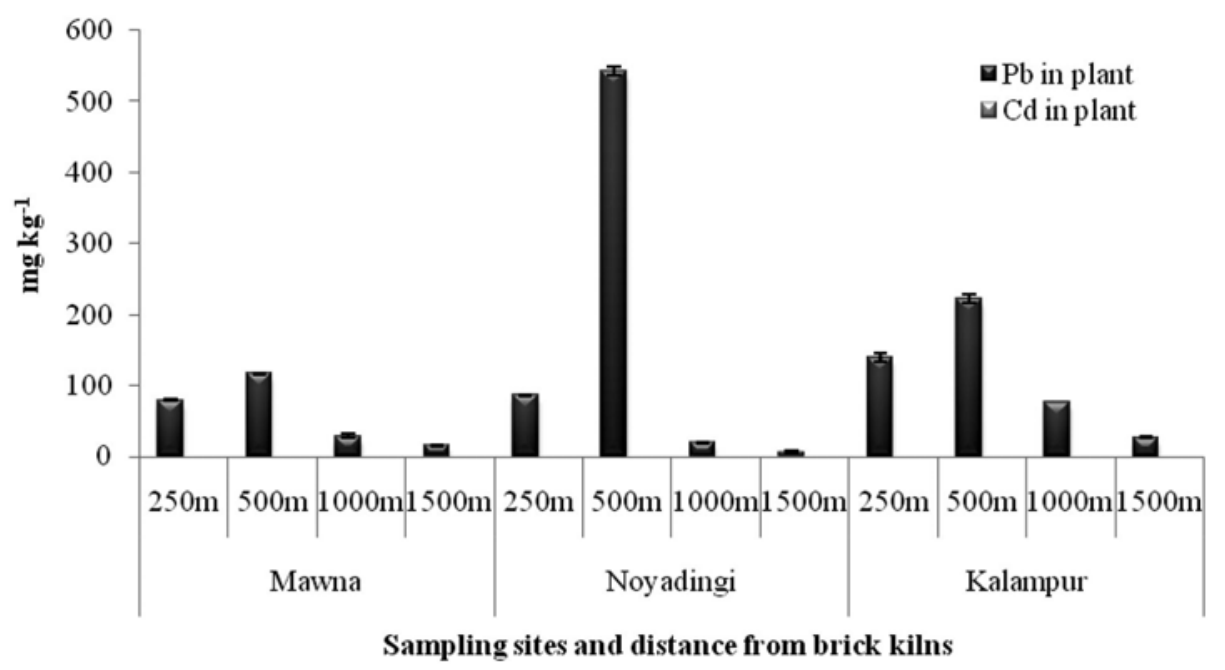

Fig. 5. Pb uptake by plants at different distance from the brick kilns.

The brick kilns were surrounded by agricultural fields far away from industry and more than $500 \mathrm{~m}$ away from the intensive vehicle used road. The parent materials of the sampling sites were Young Brahmaputra and Jamuna floodplain, which has no evidence to accumulate such pollutants. On the other hand, surface soils have higher $\mathrm{Pb}$ and $\mathrm{Cd}$ concentrations than substratum soils, indicating contaminants were not originated from the ground water. Accumulation of these contaminants also decreased with the distance from brick kilns. Hence, the only possible sources of $\mathrm{Pb}$ and $\mathrm{Cd}$ in soils were air pollution from nearby brick kilns.

\section{Conclusion}

The research provides an assessment of $\mathrm{Pb}$ and $\mathrm{Cd}$ in the agi-environment nearby brick kilns. Cadmium concentration was found within the acceptable limit in both soils and plants. On the other hand, $\mathrm{Pb}$ concentration was very high in the sampling areas. With the help of low $\mathrm{pH}$ and fly ash dumping this carcinogen accumulate higher in the nearer zones of the brick kilns and then taken up by plant. The research findings recommend that 500 to $1000 \mathrm{~m}$ distance from brick kilns might be at maximum risk in agri-environmental ecosystems since that contamination level is 
reduced with distance. Therefore, it is suggested to avoid agricultural practice up to a distance of $1000 \mathrm{~m}$ from brick kilns.

\section{References}

Ahammad, S. S., S. Siraj, M. S. Ali, M. S. Kaji and F. K. Kazi, 2010. Tracking of possible sources of Dhaka city air pollutants. Proc. of Int. Conf. on Env. Asp. of Ban (ICEAB, 10). Japan.

Ahmed, S. and I. Hossain. 2008. Applicability of air pollution modeling in a cluster of brickfields in Bangladesh. Chem. Eng. Res. Bul. 12: 28-34.

BARC, 2005. Fertilizer Recommendation Guide. Bangladesh Agricultural Research Council, Framgate, Dhaka. pp. 19-249.

Bur, T., Y. Crouau, A. Bianco, L. Gandois and A. Probst. 2012. Toxicity of $\mathrm{Pb}$ and of $\mathrm{Pb} / \mathrm{Cd}$ combination on the springtail Folsomia candida in natural soils: reproduction, growth and bioaccumulation as indicators. Sci. Total Environ. 414: 187-197.

Cavallaro, N. and M. B. McBride. 1980. Activities of $\mathrm{Cu}^{2+}$ and $\mathrm{Cd}^{2+}$ in soil solutions as affected by pH. Soil Sci. Soc. Am. J. 44: 729-732.

Chowdhury, M.T.A., L. Nesa, M.A. Kashem and S.M. Imamul Huq. 2010. Assessment of the phytoavailability of $\mathrm{Cd}, \mathrm{Pb}$ and $\mathrm{Zn}$ using various extraction procedures. Pedologist. 53(3): 80-95.

Dowdeswell, E. 1998. Extent and impacts of soil degradation on a world-wide scale. Adv. in Geoeco. 31: 8-12.

Greentech. 2012. Brick kilns performance Assessment: A Roadmap for Cleaner Brick production in India. A Shakti Sustainable Energy Foundation and Climate works foundation supported initiative, India. pp. 7-164.

Hannan, M. A. 1995. Structure and related physical properties of some soils of Bangladesh. MS thesis, Dept of Soil science, University of Dhaka, Bangladesh.

Hrudey, S.E., W. Chen and C.G. Rousseaux. 1995. Biodiversity on environmental risk assessment. Lewis Publ., Boca Raton, FL. pp. 105-375.

Jackson, M.L. 1962. Soil Chemical Analysis. Prentice Hall Inc. Englewood Cliffs. N.J., USA. pp. 498.

Khan, M.H.R., M.K. Rahman, A.J.M.A. Rouf, Y. Oki and T. Adachi. 2006. Evaluation of degradation of agicultural soils associated with brick burning in selected soil profiles in the eastern reigon of Bangladesh. Jap. J. of Trop. Agri. 50: 15-30.

Kleijn, D. and W. I. Sutherland. 2003. Review: How effective are European agri-environment schemes in conserving and promoting biodiversity? Journal of Applied Ecology 40: 947-969.

Martín, F., M. Simón, A. García and V. González. 2014. Pollution of Pb in Soils Affected by Pyrite Tailings: Influence of Soil Properties, Environmental Risk Assessment of Soil Contamination, M.C. Hernandez Soriano (Ed.), In Tech, Croatia. pp. 785-798.

Ming, H., W. H. He, D. T. Lamb, M. Megharaj and R. Naidu. 2012. Bioavailability of lead incontaminated soil depends of the nature of bioreceptor. Ecotoxicol. Environ. Saf. 78: 344-350.

Pimentel, D. 1993. World Soil Erosion and Conservation, Cambridge, UK, Cambridge University Press.

Pirkle, J. L., R. B. Kaufmann, D. J. Brody, T. Hickman, E. W. Gunter and D. C. Paschal. 1998. Exposure of the US population to lead: 1991-1994. Environ. Health Persp. 106: 745-750.

Sipos, P., T. Németh, I. Mohai and I. Dódony. 2005. Effect of soil composition on adsorption of lead as reflected by a study on a natural forest soil profile, Geoderma. 124: 363-374. 
UNDP (United Nations Development Program). 2011. Eco-friendly brick technique helps build a cleaner Bangladesh. UNDP official blog. New York. June 20, 2011.

USEPA (United States Environmental Protection Agency). 2003. Supplemental guidance for developing soil screening levels for superfund sites. U.S. Environmental protection agency, office of solid waste and emergency response, Washington, D.C.

(Manuscript received on 9 August, 2015: revised on 9 September, 2015) 